\title{
Household characteristics and allergen and endotoxin levels in Aleppo, Syrian Arab Republic
}

\author{
W. Al Ali, ${ }^{1,2}$ A. Custovic, ${ }^{1}$ A. Simpson, ${ }^{1}$ A. Khoury ${ }^{2}$ and A. Woodcock ${ }^{1}$
}

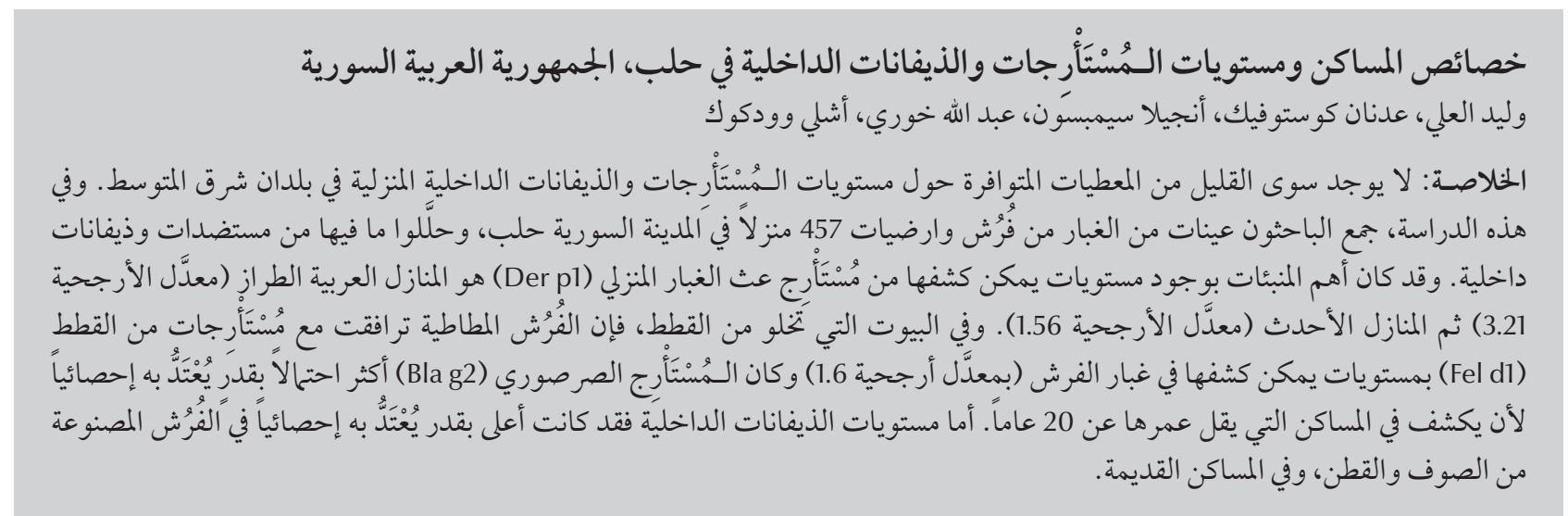

ABSTRACT Few data are available from Eastern Mediterranean countries about levels of domestic allergens and endotoxins. Dust samples were collected from mattresses and floors of 457 homes in the Syrian city of Aleppo and analysed for antigens and endotoxins. The most important predictors for detectable levels of house-dust mite allergen Der $p 1$ were Arabic-style houses (OR 3.21) and newer houses (OR 1.56). In homes without cats, rubber mattresses were associated with detectable cat allergen Fel d 1 in mattress dust (OR 1.6). Cockroach allergen Bla g 2 was significantly more likely to be detected in houses over 20 years old than newer houses. Endotoxin levels were significantly higher in wool/cotton mattresses and older houses.

\section{Caractéristiques des ménages et taux d'allergènes et d'endotoxines à Alep (République arabe syrienne)}

RÉSUMÉ Les données disponibles en matière de taux d'allergènes et d'endotoxines domestiques dans les pays de la Méditerranée orientale sont peu nombreuses. Des échantillons de poussières provenant de matelas et de sols ont été recueillis dans 457 foyers de la ville syrienne d'Alep et ont été analysés à la recherche d'antigènes et d'endotoxines. Les facteurs prédictifs les plus importants pour les taux détectables d'allergènes acariens de poussière domestique Der p 1 étaient les maisons de style arabe (odds ratio 3,21) et les maisons récentes (odds ratio 1,56). Dans les foyers ne possédant pas de chat, les matelas en mousse étaient associés à l'allergène de chat détectable Fel d 1 dans la poussière de matelas (odds ratio 1,6). L'allergène de blatte Bla g 2 était nettement plus susceptible d'être détecté dans les maisons de plus de 20 ans que dans les maisons plus récentes. Les taux d'endotoxines étaient beaucoup plus élevés dans les matelas en laine/coton et dans les vieilles maisons.

'North West Lung Research Centre, Wythenshawe Hospital, Manchester, United Kingdom (Correspondence to W. Al Ali: walid1970uk@yahoo. co.uk).

${ }^{2}$ Allergy Clinic, University of Aleppo Hospital, Aleppo, Syrian Arab Republic.

Received: 30/03/08; accepted: 28/07/08 


\section{Introduction}

Over the past 4 decades the prevalence of asthma has increased worldwide, and the debate about the causes of this have focussed on environmental exposure to pollutants and allergens in modern society [1]. Many studies in different settings have demonstrated a relationship between household characteristics and allergen levels in houses. Certain common factors seem to influence the levels of house-dust mite allergens, such as relative humidity, large numbers of occupants, older homes and dampness in the home, presence of carpets, older carpets and older mattresses [2-5]. However, not all of the variation in house-dust mite concentrations can be explained by housing characteristics alone [6].

The relationships between household characteristics and allergen concentrations in the United States were investigated by Peterson et al. [7]. Levels of the American house-dust mite allergen Der $\mathrm{f} 1$ in dust increased with increasing occupants and relative humidity, and decreased with forced-air heating. European house-dust mite allergen Der $\mathrm{p} 1$ levels were also higher with high relative humidity and with forced-air heating, but were also higher in older homes and where dogs were present. The relationship of other household characteristics was inconclusive for Der $f 1$ and Der p 1 [7]. Household endotoxin exposure is also a significant risk factor for increased prevalence of asthma [8]. However, little is known about the association between endotoxin levels and household characteristics. In a study in the United Kingdom, the indoor environment differed little between asthmatic and non-asthmatic children, but living-room carpet endotoxin levels were higher in the homes of asthmatics [9].

The association between household characteristics and allergen and endotoxin levels has only rarely been investigated in the Arab world [10]. The present study therefore aimed to investigate the association between different household characteristics and allergen and endotoxin levels in Syrian homes.

\section{Methods}

A total of 457 homes were visited in the northern Syrian city of Aleppo between July 2002 and September 2003 to interview family members and collect samples from households. The participants were recruited as a part of a larger case-control study to investigate the risk factors for asthma in the Syrian Arab Republic.

\section{Participants}

To estimate the sample size, we made an assumption that asthma prevalence in Syrian adults was about $10 \%$. With a logistic regression analysis, a study of 129 cases and 262 controls would have $>95 \%$ power to detect an odds ratio $(\mathrm{OR})$ of $\geq 2.8$ at a level of significance $<0.05$.

Phone calls and invitation letters were used to contact 300 adults aged 15 to 45 years who had been diagnosed with asthma. Of the total, 52 patients were unwilling to participate and 85 were excluded because they refused to sign the consent form. Therefore 163 asthmatics were recruited into the study: 91 from the University of Aleppo hospital allergy clinic, 26 from the chest outpatient clinic at the University of Aleppo hospital and 46 from collaborating private respiratory consultants in Aleppo. The inclusion criteria were all of the following: physiciandiagnosed asthma; asthma symptoms (wheeze, cough or both) within the previous 12 months; and use of anti-asthma medication.

For each case, 2 age-matched (to within 2 years) and sex-matched control subjects without respiratory symptoms (confirmed by an interview) were recruited within 3 weeks of enrolling a case. All controls were recruited by advertisements from among the medical and nursing students from the faculty of medicine and school of nursing and from the orthopaedic clinic of the University of Aleppo hospital. As a result of contacting 1000 subjects we received 620 responses, and after 148 refused to participate, we were able to recruit 300 controls.

\section{Home visits}

The case and control participants were pooled for this study. The homes of 457 of the 463 recruited participants were visited (6 subjects refused the home visit). Each home was visited by the investigator and a nurse to collect dust samples and data about the household environment. The data collected included: household size, presence of cigarette smokers, presence of pets, type of house (traditional Arabic courtyard design or apartment/villa), age of house (built before 1985 or after 1985), evidence of dampness (visible mould), type of heating (stove, radiators, electricity), type of cooking fuel used, presence of air-conditioning system, type of flooring and presence of carpets, type of mattresses (rubber or wool/cotton) and pillows (synthetic fibre, wool/cotton or feather) and age of mattresses and pillows.

\section{Dust sample collection}

Dust samples were collected from mattresses and kitchen floors. The bedroom mattress was inspected and any sheet covering it was removed before vacuuming the selected area for the appropriate time. Kitchen floors were vacuumed in places where dust and food remains were found, for example above the fridge, near the garbage bin, above the shelves and behind the door. A $1 \mathrm{~m}^{2}$ area was vacuumed for 2 minutes using a special dust-collection nozzle (ALK, Denmark) connected to the inlet of the suction tube of a vacuum cleaner (Samsung 800 W, Japan), with $70 \mathrm{~mm}$ filter paper which retained $74 \%$ of $0.3-0.5 \mu \mathrm{m}$ particles and up to $100 \%$ of larger particles. Immediately after 
collection, the filter papers were transferred into petri dishes and coded. Dust samples for allergen assays were stored at $4{ }^{\circ} \mathrm{C}$ until extraction. After each sample collection the head of the nozzle was cleaned using 70\% isopropyl alcohol. After sampling, each dust sample was coded showing the study number, the place sampled, the date of collection, the subject surname and initials and the presence of a cat or dog in the house.

Three dust samples were collected from each house: 2 samples from mattresses and 1 sample from the kitchen floor. Of the mattress samples 1 was kept for endotoxin analysis and 1 was analysed against dust mite and cat allergen. Kitchen floor samples were analysed for cockroach allergen only. A total of 457 kitchen dust samples, 443 mattress dust allergen samples, 435 mattress endotoxin samples were collected (14 mattress samples and 22 endotoxin samples were lost in transit).

\section{Dust sample extraction and assay}

For allergen analysis a $100 \mathrm{mg}$ aliquot of house dust was extracted by rotation with $2 \mathrm{~mL}$ borate-buffered saline with $0.1 \%$ Tween-20 pH 8.0, at room temperature $\left(20^{\circ} \mathrm{C}\right)$ for $2 \mathrm{~h}$ before being centrifuged for $20 \mathrm{~min}$ at $1200 \mathrm{~g}$ at $4^{\circ} \mathrm{C}$. The supernatant was stored at $-20^{\circ} \mathrm{C}$ untilanalysedforallergen concentration. For kitchen floor samples, we sieved the dust and then extracted the dust with the whole filter in $1 \%$ bovine serum albumin with phosphate-buffered saline solution with $0.05 \%$ Tween-20. Dust samples were assayed for house-dust mite, cat, dog and cockroach allergens using monoclonal antibody-based enzyme-linked immunoassays, and the results were expressed as detectable or not detectable, with the allergen concentration when applicable. A value of $0.05 \mu \mathrm{g} / \mathrm{g}$, was the lower limit of detection of the assay for house-dust mite (Der p 1) allergen and $0.01 \mu \mathrm{g} / \mathrm{g}$ for cat (Fel d 1), dog (Can f 1) and cockroach (Blag 2) allergens.
For endotoxin analysis dust samples were extracted with $5.0 \mathrm{~mL}$ of pyrogenfree water containing $0.05 \%$ Tween-20. Endotoxin samples were measured using a kinetic limulus amoebocyte lysate assay, and the results were expressed as endotoxin concentration (EU/mg).

\section{Statistics}

The analysis was performed using the SPSS, version 11. The allergen levels in dust reservoirs were not log-normally distributed, so the results are presented as a percentage of samples above the limit of detection. Chi-squared tests were used to analyse individual household characteristics associated with detectable allergen levels in homes. Multiple logistic regression analysis was performed to identify household characteristics that were independently associated with detectable allergen levels in homes, and odds ratios (OR) are presented. Endotoxin data were lognormally distributed and therefore were log-transformed before the analysis; results are expressed as geometric mean and $95 \%$ confidence interval (CI). Student $t$-tests and 1-way analysis of variance tests were performed to compare groups. The level of significance was $P$ $<0.05$.

\section{Results}

\section{Household characteristics}

Ofthe 463 homes, $86 \%$ were apartments or flats, $13 \%$ were houses of traditional Arabic design and $1 \%$ were villas; $37 \%$ of homes were $<20$ years old, the majority with 1 or 2 bedrooms (79\%). Almost one-quarter of households (23\%) had $6+$ occupants. Almost all bedrooms (99\%) had marble or concrete floors, but $73 \%$ of rooms contained a rug in winter. Air-conditioning was used in summer in $82 \%$, and gas was almost exclusively used for cooking (98\%). Visible damp was identified in $37 \%$ of homes. Mattresses were rubber (60\%) or cotton/wool (40\%). Pillows were cotton/wool (69\%), synthetic (29\%) or feather (2\%).

\section{House-dust mite allergen}

The house-dust mite allergen Der p 1 was detected at a significantly higher rate in Arabic-style houses than in apartments $(P<0.001)$ and in newer-built homes compared with older homes $(P<0.01)$ (Table 1). The Derp 1 detection rate was higher in new mattresses than old mattresses $(P<0.05)$ but did not differ by type of mattress or pillow. Bedrooms which contained a rug had a higher rate of detection of Der $\mathrm{p} 1$ mite allergens in the mattress $(P<0.01)$. Homes with gas fires $(P<0.01)$ and visible dampness $(P<0.01)$ were more likely to have detectable levels of Der $p$ 1 but presence of air-conditioning had no effect. Number of occupants also had no significant effect on the rate of detection of Derp 1.

In the multivariate analysis, the independent associates of detectable Der p 1 in the mattresses were Arabic-style house (OR 3.21; 95\% CI: 1.64-6.30, $P<0.001$ ) and newer house (OR 1.56, $95 \%$ CI: $1.07-2.27, P=0.02$ ).

\section{Cat allergen}

The cat allergen Fel $\mathrm{d} 1$ was found at significantly higher rates in older homes $(P<0.01)$, without air-conditioning $(P<0.001)$ and with heating by radiators or electricity $(P<0.001)$. Higher rates of detectable cat allergen were found in rubber mattresses $(P<0.05)$ and older mattresses $(P<0.05)$ (Table 2$)$.

In the multivariate logistic regression analysis, the only independent predictor of the presence of Fel d 1 in mattresses was having a cat in the home (OR 6.04, 95\% CI: 1.98-18.49, $P=0.002)$. When restricted to homes without cats, the only independent predictor was a rubber mattress (OR 1.6, 95\% CI: $1.04-2.32, P<0.01)$.

As expected, homes that kept cats had a significantly higher detection rates for the cat allergen Fel $\mathrm{d} 1$ in mattress dust than homes without a cat 


\begin{tabular}{|c|c|c|c|c|}
\hline \multirow[t]{2}{*}{ Household characteristic } & \multirow[t]{2}{*}{ No. of samples } & \multicolumn{2}{|c|}{ Der $P 1$ allergen detected } & \multirow[t]{2}{*}{$P$-value } \\
\hline & & No. & $\%$ & \\
\hline \multicolumn{5}{|l|}{ House type } \\
\hline Arabic & 60 & 21 & 35.0 & $<0.001$ \\
\hline Apartment & 379 & 50 & 13.2 & \\
\hline \multicolumn{5}{|l|}{ House age (years) } \\
\hline$<10$ & 52 & 15 & 28.8 & 0.006 \\
\hline $10-20$ & 114 & 20 & 17.5 & \\
\hline$>20$ & 277 & 36 & 13.0 & \\
\hline \multicolumn{5}{|l|}{ Mattress type } \\
\hline Wool/cotton & 177 & 32 & 18.1 & 0.3 \\
\hline Rubber & 264 & 38 & 14.4 & \\
\hline \multicolumn{5}{|l|}{ Mattress age (years) } \\
\hline$<1$ & 74 & 16 & 21.6 & 0.05 \\
\hline $1-3$ & 130 & 23 & 17.7 & \\
\hline $3-5$ & 42 & 8 & 19.0 & \\
\hline$>5$ & 197 & 24 & 12.2 & \\
\hline \multicolumn{5}{|l|}{ Pillow type } \\
\hline Wool/cotton & 307 & 51 & 16.6 & 0.85 \\
\hline Synthetic fibre & 125 & 19 & 15.2 & \\
\hline \multicolumn{5}{|l|}{ Bedroom floor } \\
\hline With rug & 323 & 61 & 18.9 & 0.007 \\
\hline Without rug & 120 & 10 & 8.3 & \\
\hline \multicolumn{5}{|l|}{ Visible mould } \\
\hline Yes & 166 & 37 & 22.3 & 0.005 \\
\hline No & 277 & 34 & 12.3 & \\
\hline \multicolumn{5}{|l|}{ Air conditioning } \\
\hline Yes & 363 & 61 & 16.8 & 0.34 \\
\hline No & 80 & 10 & 12.5 & \\
\hline \multicolumn{5}{|l|}{ Heating } \\
\hline Stove & 277 & 55 & 19.9 & 0.01 \\
\hline Radiator & 109 & 8 & 7.3 & \\
\hline Electricity & 56 & 8 & 14.3 & \\
\hline \multicolumn{5}{|c|}{ Household size (no. of occupants) } \\
\hline$\leq 6$ & 378 & 59 & 15.6 & 0.5 \\
\hline$>6$ & 65 & 12 & 18.5 & \\
\hline
\end{tabular}

$\mathrm{P}<0.05$ considered significant.

$(P<0.001)$. However, Feld 1 was highly dispersible, as some homes without cats contained high levels of Fel d 1 possibly by passive exposure. For homes with a cat and detectable Fel d 1, the actual geometric mean Fel $\mathrm{d} 1$ level was $0.14 \mu \mathrm{g} / \mathrm{g}(95 \%$ CI: $0.05-0.42 \mu \mathrm{g} / \mathrm{g})$ (Figure 1). In $4 / 22$ homes with cats and 241/421 homes without cats the samples were below the detection limit.
Only 1 home contained a dog and heating, air-conditioning, household therefore no data are presented for dog- size or the presence of damp. mite allergen.

\section{Cockroach}

Older homes had significantly higher detection rates of the cockroach allergen Bla g $2(P<0.01)$ (Table 3$)$. There was no association between presence of the cockroach allergen and type of house,

\section{Endotoxin}

From 430 detectable mattress samples there were 2 samples above the detection limit (endotoxin levels of $>1000$ $\mathrm{EU} / \mathrm{mg}$ despite 2 dilutions). There was a trend towards higher levels of endotoxin in Arabic-style houses and 


\begin{tabular}{|c|c|c|c|c|}
\hline \multirow{2}{*}{ Household characteristic } & \multirow[t]{2}{*}{ No. of samples } & \multicolumn{2}{|c|}{ Fel d 1 detected } & \multirow[t]{2}{*}{$P$-value } \\
\hline & & No. & $\%$ & \\
\hline \multicolumn{5}{|l|}{ House type } \\
\hline Arabic & 60 & 29 & 48.3 & \multirow{2}{*}{0.5} \\
\hline Apartment & 379 & 167 & 44.1 & \\
\hline \multicolumn{5}{|l|}{ House age (years) } \\
\hline$<10$ & 52 & 16 & 30.8 & \multirow{3}{*}{0.04} \\
\hline $10-20$ & 114 & 50 & 43.9 & \\
\hline$>20$ & 277 & 132 & 47.7 & \\
\hline \multicolumn{5}{|l|}{ Mattress type } \\
\hline Wool/cotton & 177 & 69 & 39.0 & \multirow{2}{*}{0.03} \\
\hline Rubber & 264 & 129 & 48.9 & \\
\hline \multicolumn{5}{|l|}{ Mattress age (years) } \\
\hline$<1$ & 74 & 30 & 40.5 & \multirow{4}{*}{0.02} \\
\hline $1-3$ & 130 & 50 & 38.5 & \\
\hline $3-5$ & 42 & 16 & 38.1 & \\
\hline$>5$ & 197 & 102 & 51.8 & \\
\hline \multicolumn{5}{|l|}{ Pillow type } \\
\hline Wool/cotton & 307 & 127 & 41.4 & \multirow{2}{*}{0.1} \\
\hline Synthetic fibre & 125 & 64 & 51.2 & \\
\hline \multicolumn{5}{|l|}{ Bedroom floor } \\
\hline With rug & 323 & 142 & 44.0 & \multirow{2}{*}{0.6} \\
\hline Without rug & 120 & 56 & 46.7 & \\
\hline \multicolumn{5}{|l|}{ Air conditioning } \\
\hline Yes & 363 & 145 & 39.9 & \multirow{2}{*}{$<0.001$} \\
\hline No & 80 & 53 & 66.3 & \\
\hline \multicolumn{5}{|l|}{ Heating } \\
\hline Radiator & 109 & 64 & 58.7 & \multirow{3}{*}{$<0.001$} \\
\hline Electricity & 56 & 28 & 50.0 & \\
\hline Stove & 277 & 105 & 37.9 & \\
\hline \multicolumn{5}{|l|}{ Cat ownership } \\
\hline With cat & 22 & 18 & 81.8 & \multirow{2}{*}{$<0.001$} \\
\hline Without cat & 421 & 180 & 42.8 & \\
\hline
\end{tabular}

$\mathrm{P}<0.05$ considered significant.

older houses but this was not statistically significant. Endotoxin levels were significantly higher in wool/cotton mattresses $(P<0.001)$ andin newmattresses $(P<0.01)$, but not with visible mould, type of pillows or type of heating (Table 4).

In the multivariate analysis, independent predictors of high endotoxin levels in mattresses were: wool/cotton mattresses (GM 31.7\%, 95\% CI: 26.2\%$38.4 \%, P<0.001$ ) and older houses (GM $28.7 \%, 95 \%$ CI: $24.2 \%-34.0 \%, P=0.03$ ).

\section{Discussion}

This is the first large study to investigate the relationship between housing characteristics and allergen and endotoxin levels in a Middle Eastern country. Our data suggest that Arabic-style houses and newer houses were the most important predictors for detectable levels of house-dust mite allergen Der $\mathrm{p}$ 1. The Arabic house is unique in both design and structural materials. It usually has an open-air courtyard and multiple families in the same house. Arabic houses are built by using mud and wood, the floor may be mud or hard cement or covered by tiles/marble and there is no system to control the indoor temperature and humidity. Modern utilities are not adapted for this type of house, and this may contribute to a suitable environment for house-dust mite growth [2]. Newer houses were also more likely to have high detection rates of house-dust mite allergens as they are more likely be heated in winter, which, together with 


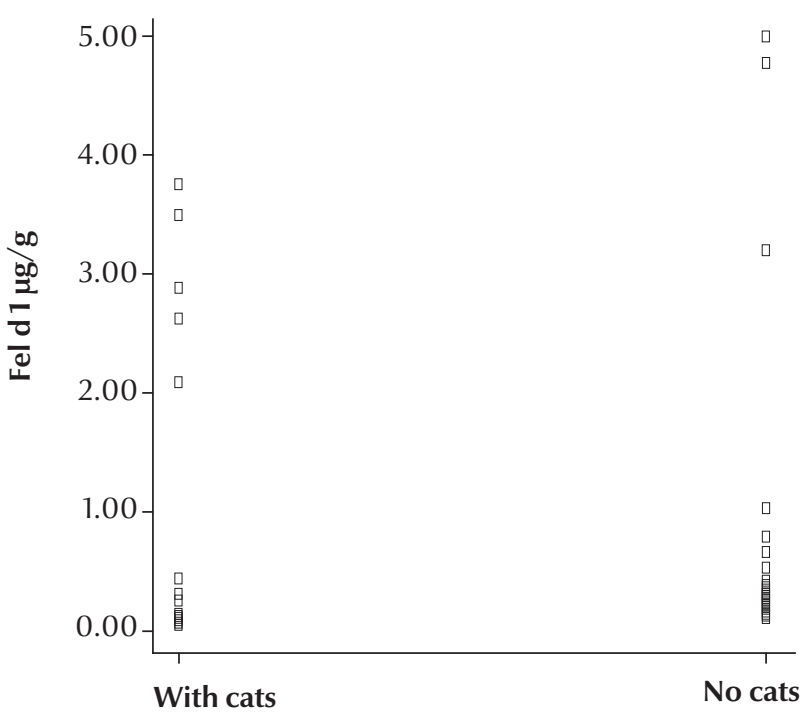

Figure 1 Distribution of mean levels of cat allergen Fel $\mathbf{d} 1$ in dust samples from homes with and without a cat

reduced ventilation, may make them liable to house-dust mite infestation. This is consistent with modern houses and modern energy systems, where reduced ventilation results in higher humidity, which makes them a more suitable environment for the proliferation of dust mites [2].
Pet ownership is rare in the Syrian Arab Republic. In our study different housing characteristics were shown to influence the presence of the cat allergen Fel $\mathrm{d} 1$ in Syrian homes, such as the presence of modern heating systems and the absence of air-conditioning. But by far the most important factor was the presence of a cat. When homes without cats were analysed separately, the presence of rubber mattresses was the only independent factor to influence the detection of the Fel 11 allergen. Our data are consistent with those of other studies [7,11-13]

Older homes (built before 1985) were more likely to have detectable cockroach allergen, possibly because old houses tend have higher occupancy rates and damaged structures which provide suitable habitats for cockroach infestation.

High endotoxin levels in Syrian homes were associated with wool/

\begin{tabular}{|c|c|c|c|c|}
\hline \multirow[t]{2}{*}{ Household characteristic } & \multirow[t]{2}{*}{ No. of samples } & \multicolumn{2}{|c|}{ Bla g 2 allergen detected } & \multirow[t]{2}{*}{$P$-value } \\
\hline & & No. & $\%$ & \\
\hline \multicolumn{5}{|l|}{ House type } \\
\hline Arabic & 61 & 17 & 27.9 & \multirow{2}{*}{0.7} \\
\hline Apartment & 392 & 99 & 25.3 & \\
\hline \multicolumn{5}{|l|}{ House age (years) } \\
\hline$<10$ & 54 & 7 & 13.0 & \multirow{3}{*}{0.003} \\
\hline $10-20$ & 117 & 25 & 21.4 & \\
\hline$>20$ & 286 & 85 & 29.7 & \\
\hline \multicolumn{5}{|l|}{ Visible mould } \\
\hline Yes & 170 & 48 & 28.2 & \multirow{2}{*}{0.3} \\
\hline No & 287 & 69 & 24.0 & \\
\hline \multicolumn{5}{|l|}{ Heating } \\
\hline Stove & 285 & 69 & 24.2 & \multirow{3}{*}{0.5} \\
\hline Radiator & 112 & 32 & 28.6 & \\
\hline Electricity & 59 & 16 & 27.1 & \\
\hline \multicolumn{5}{|l|}{ Air conditioning } \\
\hline Yes & 374 & 96 & 25.7 & \multirow{2}{*}{0.5} \\
\hline No & 83 & 21 & 25.3 & \\
\hline \multicolumn{5}{|l|}{ Household size } \\
\hline$\leq 6$ & 389 & 101 & 26.0 & \multirow{2}{*}{0.7} \\
\hline$>6$ & 68 & 16 & 23.5 & \\
\hline
\end{tabular}

$P<0.05$ considered significant. 


\begin{tabular}{|c|c|c|c|c|}
\hline \multirow[t]{2}{*}{ Household characteristic } & \multirow[t]{2}{*}{ No. of samples } & \multicolumn{2}{|c|}{ Endotoxin levels EU/mg } & \multirow[t]{2}{*}{$P$-value } \\
\hline & & Geometric mean & $95 \% \mathrm{Cl}$ & \\
\hline \multicolumn{5}{|l|}{ House type } \\
\hline Arabic & 60 & 29.2 & $21.9-38.8$ & \multirow{2}{*}{$0.1^{\mathrm{a}}$} \\
\hline Apartment & 366 & 23.7 & $21.6-25.9$ & \\
\hline \multicolumn{5}{|l|}{ House age (years) } \\
\hline$<10$ & 54 & 21.2 & $16.9-26.5$ & \multirow{3}{*}{$0.3^{\mathrm{b}}$} \\
\hline $10-20$ & 114 & 23.3 & $19.1-28.4$ & \\
\hline$>20$ & 262 & 25.6 & $23.0-28.4$ & \\
\hline \multicolumn{5}{|l|}{ Mattress type } \\
\hline Wool/cotton & 174 & 32.9 & $28.4-38.2$ & \multirow{2}{*}{$<0.001^{\mathrm{a}}$} \\
\hline Rubber & 254 & 19.9 & $18.0-22.0$ & \\
\hline \multicolumn{5}{|l|}{ Mattress age (years) } \\
\hline$<1$ & 72 & 33.8 & $27.2-42.1$ & \multirow{4}{*}{$0.005^{\mathrm{b}}$} \\
\hline $1-3$ & 126 & 23.9 & 20.1-28.7 & \\
\hline $3-5$ & 45 & 25.7 & $19.0-34.6$ & \\
\hline$>5$ & 187 & 21.4 & $19.1-24.2$ & \\
\hline \multicolumn{5}{|l|}{ Pillow type } \\
\hline Wool/cotton & 302 & 25.4 & $23.0-28.0$ & \multirow{2}{*}{$0.3^{\mathrm{a}}$} \\
\hline Synthetic fibre & 120 & 23.0 & $20.0-26.0$ & \\
\hline \multicolumn{5}{|l|}{ Bedroom floor } \\
\hline With rug & 313 & 24.9 & $22.4-28.0$ & \multirow{2}{*}{$0.4^{\mathrm{a}}$} \\
\hline Without rug & 117 & 22.9 & $19.5-27.0$ & \\
\hline \multicolumn{5}{|l|}{ Visible mould } \\
\hline Yes & 155 & 25.6 & 21.8-29.9 & \multirow{2}{*}{$0.4^{\mathrm{a}}$} \\
\hline No & 275 & 23.7 & $21.4-26.3$ & \\
\hline \multicolumn{5}{|l|}{ Heating } \\
\hline Gas stove & 271 & 25.0 & $22.0-28.0$ & \multirow{3}{*}{$0.1^{\mathrm{b}}$} \\
\hline Radiator & 104 & 21.2 & $18.0-25.0$ & \\
\hline Electricity & 54 & 28.4 & $22.0-37.0$ & \\
\hline \multicolumn{5}{|l|}{ Air conditioning } \\
\hline Yes & 356 & 24.0 & $22.0-27.0$ & \multirow{2}{*}{$0.5^{\mathrm{a}}$} \\
\hline No & 74 & 26.2 & $21.3-32.0$ & \\
\hline \multicolumn{5}{|l|}{ Household size } \\
\hline$\leq 6$ & 362 & 24.3 & $22.1-26.7$ & 0 a \\
\hline$>6$ & 68 & 24.9 & $19.8-31.4$ & $0.8^{a}$ \\
\hline No. of bedrooms & & & & \\
\hline$\leq 2$ & 337 & 24.6 & $22.4-27.1$ & ○ 6а \\
\hline$>2$ & 93 & 23.4 & 19.0-28.7 & $0.6^{2}$ \\
\hline No. of people sharing same & & & & \\
\hline 0 & 64 & 22.9 & $17.8-29.4$ & \\
\hline 1 & 150 & 23.3 & $20.1-27.0$ & $03 \mathrm{~b}$ \\
\hline 2 & 108 & 23.3 & $19.5-27.8$ & $0.3^{\mathrm{D}}$ \\
\hline$>2$ & 108 & 28.1 & $23.7-33.2$ & \\
\hline Pet ownership & & & & \\
\hline With cat & 18 & 19.0 & $12.3-29.5$ & 0 วа \\
\hline Without cat & 412 & 24.7 & $22.6-26.9$ & $0.2^{a}$ \\
\hline
\end{tabular}

${ }^{a}$ Student $\mathrm{t}$-test; ${ }^{b} 7$-way analysis of variance.

$E U=$ endotoxin unit; $C I=$ confidence interval. 
cotton mattresses and older houses. Unlike a study in Germany [14] the present data suggest that endotoxin levels increase with the decreasing age of mattresses. The reason for this is not clear. It may be that new mattresses with synthetic materials favour bacterial growth or that porous fabrics allow higher rates of sampling during vacuuming. We did not associate endotoxin with visible dampness, in agreement with one previous study [15] but in contrast with others $[10,16,17]$. Although homes with a cat had slightly higher endotoxin levels than those without a cat, the difference was not statistically significant. This may reflect the infrequent cat ownership in the Syrian Arab Republic and the even lower ownership of dogs.

In conclusion, these data indicate that while indoor allergen levels are low in Syrian households, there are important household characteristics that influence both allergen and endotoxin levels. Some of these unique features may be amenable to change, while others are not (house type). More research is needed to elucidate the contribution of these factors to the prevalence of atopy and asthma in the Syrian Arab Republic.

\section{Acknowledgements}

Many thanks to Mr Mark Craven, Dr Gael Tavernier and Mrs Julie Morris for their assistance, and for the Ministry of Higher Education in Syrian Arab Republic for funding this study.

\section{References}

1. Selgrade MK et al. Induction of asthma and the environment: what we know and need to know. Environmental Health Perpectives, 2006, 114(4):615-619.

2. Simpson A, Woodcock A, Custovic A. Housing characteristics and mite allergen levels: to humidity and beyond. Clinical and Experimental Allergy, 2001, 31(6):803-805.

3. Van Strien RT et al. Mite antigen in house dust: relationship with different housing characteristics in the Netherlands. Clinical and Experimental Allergy, 1994, 24(9):843-853.

4. Wickens $\mathrm{K}$ et al. Determinants of house dust mite allergen in homes in Wellington, New Zealand. Clinical and Experimental Allergy, 1997, 27(9):1077-1085.

5. Chan-Yeung $M$ et al. House dust mite allergen levels in two cities in Canada: effects of season, humidity, city and home characteristics. Clinical and Experimental Allergy, 1995, 25(3):240-246.

6. Van Strien RT et al. The influence of air conditioning, humidity, temperature and other household characteristics on mite allergen concentrations in the northeastern United States. Allergy, 2004, 59(6):645-652.

7. Peterson EL, Ownby DR, Johnson CC. The relationship of housing and household characteristics to the indoor concentrations of Der f 1, Der p 1, and Fel d 1 measured in dust and air samples. Annals of Allergy, Asthma and Immunology, 2003, 90(5):564-571.

8. Thorne PS et al. Endotoxin exposure is a risk factor for asthma: the national survey of endotoxin in United States housing.
American Journal of Respiratory and Critical Care Medicine, 2005, 172(11):1371-1377.

9. Tavernier $\mathrm{G}$ et al. IPEADAM study: indoor endotoxin exposure, family status, and some housing characteristics in English children. Journal of Allergy and Clinical Immunology, 2006, 117(3):656-662.

10. El Sharif $\mathrm{N}$ et al. Concentrations of domestic mite and pet allergens and endotoxin in Palestine. Allergy, 2004, 59(6):623-631.

11. Fahlbusch BL et al Allergens in house dust samples in Germany: results of an East-West German comparison. Allergy, 1999, 54(11):1215-1222.

12. Fahlbusch B et al. Predictors of cat allergen (Fel d 1) in house dust of German homes with/without cats. Journal of Investigational Allergology and Clinical Immunology, 2002, 12(1):12-20.

13. Giovannangelo $\mathrm{M}$ et al. Childhood cat allergen exposure in three European countries: the AIRALLERG study. Science of the Total Environment, 2006, 369(1-3):82-90.

14. Gehring $U$ et al. Levels and predictors of endotoxin in mattress dust samples from East and West German homes. Indoor Air, 2004, 14(4):284-292.

15. Gereda JE et al. Metropolitan home living conditions associated with indoor endotoxin levels. Journal of Allergy and Clinical Immunology, 2001, 107(5):790-796.

16. Bischof $\mathrm{W}$ et al. Predictors of high endotoxin concentrations in the settled dust of German homes. Indoor Air, 2002, 12(1):2-9.

17. Wickens $\mathrm{KJ}$ et al. Determinants of endotoxin levels in carpets in New Zealand homes. Indoor Air, 2003, 13(2):128-135. 